\title{
Discussion on the Methods of Modern Landscape Planning and Design for the Protection of Ecological Environment
}

\author{
Hong Wang \\ Department of Environmental Design \\ Eastern International Art College \\ Zhengzhou University of Light Industry \\ Zhengzhou, China
}

\begin{abstract}
The concept "no design" and "non-existent design" on modern urban landscape design considers modern landscape design as an interconnected green spatial network consisting of various open space and natural regions including greenway, waterway, wetland, woodland, park, wildlife habitat, forest, plantation, pasture and wasteland, etc. As key parts of urban natural life support system, they all can provide a start and an end for wild life migration and ecological process. The system itself is capable of naturally managing rainstorms and reducing the hazard of deluges and lakes and improving water environmental quality. Besides of the ecological benefits, considerable economic and social benefits can be created by the system for saving the resources of municipal construction so that to reduce costs of urban management and promote its land value.
\end{abstract}

Keywords-ecological crisis; urban landscape; new rural reconstruction; no design

\section{CONCEPT OF ENVIRONMENTAL ECOLOGICAL CRISIS}

\section{A. Concept of Environmental Ecological Crisis in Landscape} Design

Ecological crisis refers to the phenomenon that seriously damage in ecological environment threatens the survival and development of human beings, also resulting from the malignant developmental dysbiosis at the same time. As it will be difficult to recover within a long period of time once the ecological crisis forming, people should be alert in its latency stage. The destruction of ecological balance, since which is mainly caused by human, will be overcome and eliminated with the development of human society.

The environmental ecological crisis in landscape design embodies in three aspects: the natural landscape ecological crisis, social landscape ecological crisis and human landscape ecological crisis. The modern urban environmental ecological crisis is the result of people's constant choices between constructing landscapes and improving urban residential environment, that of make use of valuable landscape effect to create more profits or use landscape effects to establish its city image. No matter how to choose, obviously urban symbol characteristics are decreasing; people's traditional life styles changing; social humanistic environment fading out and, the most terrible part, all the cities are about to wear the same mask. These are the environmental ecological crisis brought by urban construction and urban landscape design which will affect the environmental ecological system of the whole city not only plants and animals, but humankind themselves.

\section{B. The Formation of Environmental Ecological Crisis in Landscape Design}

How the city we live now develops, how the landscape adjusts to the development of cities and what will be the development prospect. Following the improvement of people's living standards, mechanization large-scale production has caused more carbon emission, which leads to more and more sandstorms and hazes in our cities now; abandoned rubbish has polluted rivers, which may further pollute the whole water area even the water system. The blue sky, white clouds and green grasses in our memory of childhood have gradually faded away, instead, a large number of south palms are transplanted to our north cities and many exotic types of vegetation are adopted in the landscape plant configuration. Actually, it is these tough replicated landscape designs which counterfeit pseudo regional characteristic landscape that are destroying the local natural landscape and ecological system.

For example, for the landscape plant configuration in Zhengzhou-Kaifeng logistics corridor in the construction of Zhengzhou-Kaifeng integration, most shrubs are ligustrum quihoui and ligustrum lucidum cv. Besides that, bamboos, ginkgoes and cercis chinensis, etc. are also planted there. After several years of cultivation, we find that in Zhongmou the gap of flower bed will be full of the local dog tail grasses whose vitality is extremely exuberant in every spring and summer. To maintain the landscape effect, it is necessary to ask the nearby villagers for help to remove these "weeds" from morning till night every day. What is the real value of the landscape requiring of much money and manpower to maintain its effects? Does this landscape with high costs of maintenance construct the landscape or destroy it? 


\section{The Influence of Environmental Ecological Crisis on Landscape Design}

Modern landscape design develops till now, we cannot help questioning that the landscapes designed by us makes environment evolve or degenerate, and the embodiment of human history in landscape design inherits or changes the traditional culture. In the process of the social life development, and the "evolution" of landscape design itself mostly aims to solving the problem of adaptation of people's living environment, which seemingly cannot solve the problem of civilization and progress, thus, new problem of environmental survival crisis will arise.

Actually, the replicated landscape will destroy not only the natural landscape ecological system but also the local human historical style, which means, the traditional life style of local people will also change. While all these things destroyed by improper landscape design are just individual symbols and cityscapes of the city. If the city loses its own characteristics, its "evolution" will really become "involution".

\section{CURRENT SituAtion OF URBAN LANDSCAPE DESIGN}

\section{A. The Concept of Urban Landscape Design}

Great disparities exist between eastern and western cultural traditions. In architecture, Chinese people prefer acting according to circumstances and using local materials such as natural timber to build houses, while westerners prefer using stones to build houses from the very first. It is the same when reflecting on the landscape design. For the landscape practice, Chinese people pursue on the concept "Unity of man and nature", using nature and returning to nature. Taking the Summer Palace in Beijing as an example, where artificial natural environment was formed through the echo of Longevity Hill and Collina del Carbone, as well as drawing water and opening up ditches and gutters; whereas western people are particular to the concept of "Man can conquer nature" and stress that human powers are able to change nature, for example, the geometric shape of Palace of Versailles in Paris.

\section{B. Current Situation of Urban Landscape Design}

In the west, reproduction is forbidden or laughed by others; while in domestic design circles, many reproductions are regard as the first and best choice. Since some of designs have been done by others and obtained great success, some young landscape designers adopt some certain successful cases and considered them as the shortcut for success. Therefore, we have seen many uniform designs of urban landscapes as well as some new rural reconstruction projects. Some certain successful cases in urban landscape and the native plants of this successful case are adopted to a number of other cities to achieve the effect of apparent success. However, they do not know that this method is destroying the humanities, histories and natural territory of these cities, and invisibly destroying the local ecological and natural environment. It is just the usage of landscape design artificially causing urban environmental ecological crisis.
1) Landscape Design of Urban Residential District: Bianca Bosker, an executive editor of The Huffington Post (JCR Science Edition), writes a book named Original Copies: Architectural Mimicry in Contemporary China. The book discusses on the trend of Chinese "copycat buildings". "I think that the 'reality' of Chinese architectures do not mean building the quadrangle courtyard or the Shikumen. Some developers have built the theme communities according to the template of traditional Chinese architecture. Cathay View Villa in Beijing or the Fifth Park in Hangzhou absorbs more native architectural style, which is also another way for developers to distinguish their products in increasingly crowded real estate markets. However, these communities are not the exact replicas of Chinese traditional housing usually having floor layouts much similar to those in the West, while only the exterior is more "Chinese-style."

As a matter of fact, in the landscape design of developing in modern residential area, developers and designers have also begun their own deliberations and discussions. No matter their purposes are to distinguish the differences between theirs and others or to inherit and explore traditional culture, now people have realized that they will be in a pickle and unable to extricate if replicating persistently. To develop further, it is necessary to have its own native cultural characteristics for the sustainable development, which is the same with landscape design.

2) Landscape Design of the New Rural Reconstruction: In order to improve the quality of life of the rural population, all regions start to pull down and reconstruct the houses in order to develop the local economy for land development, so that the farmer can live into apartment houses like urban communities. But the following problems such as difficulty of employment, land loss and folk culture, has created much more serious impacts on local ecological environment degeneration and a series of problems. The purpose of the new rural reconstruction itself is to improve people's life quality but not to undermine the living environment. So in this respect, all regions during construction might as well refer to the upgrading and reconstruction project of Guojiagou village in Tianjin.

Guojiagou village is located in scenic mountain areas of Ji County in Tianjin with mountains surrounded. Landscape design project of this place mainly includes refurbishment of buildings, landscape planning, drainage of water system, humanities inheritance and other aspects, which also has made a comprehensive planning and design about the ecological protection, green space system, soil remediation of the local environment and even social ecology, so that the local culture and architectural features are inherited and carried forward originally. In addition, local terrace, built with local stones and dredged by local original river system, continues to be used in the design and building of landscape, which enables the preservation and presentation of the true features of natural texture, also the medicinal materials are planted according to the features of local vegetation, so as to increase local farmers' income while beautifying the scenery. 


\section{Reflection on Urban Landscape Design}

What concepts should be contained in urban landscape design on earth? And what is the value of landscape design? In design we always say that "man is the yardstick of everything and everything is the mirror of man". There is no exception in landscape design. Greening, facility and function series in landscape need targeted arrangement and design for users in different ages and gender. Also, people's subjective thinking, such as local traditional culture, folk concepts, architectural features and materials, etc., also will be reflected in the landscape design due to people's psychological and aesthetic needs. Therefore we should keep the concept of "people oriented and adjusting measures to local conditions" in landscape design. The value of urban landscape lies in providing the opportunities for urban residents to closely contact with nature, and creating a good environment for the people, so as to meet people's desires in their most primitive subconscious for returning to nature.

\section{DESIGN TREND OF MODERN URBAN LANDSCAPE}

\section{A. The Concept of Modern Urban Landscape Design}

Such sentences are mentioned in the prose Jiang Yan's Ode to Departure, that "The earth hears of Shaoyao poem and Jiaren songs, that spoony lovers are chanting for beauty Wei in Shangzhong and Chen in Shanggong. Even if spring generates green grasses and adorable green waves, sending you to Nanpu will drown me in endless sorrows." And there are sentences that "Grasping your hand, I swim towards east for sending my lover to Nanpu." in a poem He Bo of Nine Songs from Elegies of Chu. Both of them mentioned "Nanpu" which refers to the water on the south, a departure place for people to send their relatives and friends off in the ancient time. People will feel sad about departing if seeing "Nanpu" reminds people of departure which are likely to bring sadness. The poems not only pointed out the departing site, but expressed their feelings through the description of scene to render the strong sorrowful feelings of departure and then combine scene with feelings perfectly. These sceneries described in the poems of Chinese ancients have already disappeared in the long river of history.

So to design a reasonable landscape in a pleasant environment which enable to decorate the scenery and match people's feelings, and to design "picturesque" modern landscape as ancient poetry, our designers are necessary to absorb the essence from traditional gardening art again. So in the modern urban landscape design, the idea "no design" and "non-existence design" of landscape design proposed now are similar to the concept "Unity of Man and Nature" in the building of our Chinese traditional gardens.

The idea "no design" and "non-existence design" aims to design the modern urban landscape as an interconnected green spatial network, which consists of various open space and natural region including greenway, waterway, wetland, woodland, park, wildlife habitat, forest, plantation, pasture and wasteland, etc. They are all key parts of urban natural life support system which can be the beginning and ending of wildlife migration and ecological process. The system itself is able to naturally manage storm, reduce the hazard of Honghu water and improve water environmental quality. Besides ecological benefits, it can bring considerable economic and social benefits, for saving the resources of municipal construction and the costs of urban management, and promoting the value of land.

\section{B. The Content of Modern Urban Landscape Design}

Urban environmental landscape design is a huge system including various contents, among which one important aspect is the landscape design of city public open space. These public open spaces have become the major places for more and more people to relax and communicate due to the growing important role of its characteristic of openness in the city life. These spaces mainly include following several kinds: road, square, garden and waterfront, etc. After concluding all aspects of contents of the landscape, we could put forward some methods of green landscape and ecological landscape in urban landscape design. The methods include: low-impact exploration model, natural habitat conservation, wetland conservation, and drainage of ecological river, drainage of ecological road, establishment of green space system, soil remediation, overall environmental renovation and other aspects.

\section{The Method of Modern Urban Landscape Design}

Natural ecological protection can put the design methods and concepts of ecological infrastructure into practice to prevent landscape project from destroying the natural ecology and improve the environment on many aspects. For example, designing road ecological drainage grassy trenches for generating plants and conserving groundwater; dredging and draining the water and excavating reservoir which can implement efficient recycling of water system; adopting native plants and local building materials which is the best choice to comply with local environment and can also reduce the emissions from transport; at the same time when reconstructing the old housings, building energy efficiency will be realized from insulating layer, new roof and window, interior function set, utilization of decorative materials and other aspects.

In social ecological protection we should regard "society" as an ecological system; meanwhile it is a necessary element of the landscape ecological system. Vivid landscape should not be created without human, only in this way the design and construction of landscape is valuable. The hominine element is necessary in a "picturesque" landscape design. So in the landscape design, the balance and stability of developing social ecological system should be kept. There is no doubt that largescale demolition will destroy the stable social ecological system, so it is important to explore and practice the new path of in-situ promotion, reforming, urbanization and civilization, in order to benefit both government and farmers and make society stabile and united.

In cultural ecology, cultural ecology refers to some special cultural characteristics and patterns with regional differences. In the past large-scale demolition and construction, historic culture disappeared with these demolished buildings. Designers can insist on their own ideas of retaining the local traditional architectural mode and cultural kernel in the 
landscape design of urban or the new rural reformation. The methods of landscape design insist on local architectural form, construction technology, architectural language and landscape element; in new-built public buildings there are workshop, pavilion and gift shop to carry forward local art; in-situ promotion and reforming and keeping way of life formed by people's ancestors will make it to be alive culture.

\section{The Trend of Modern Urban Landscape Design}

Landscape design exists as a test, just as a pyramid, and from the very beginning arises from sticking to the definition and bottom line of human to embodying wisdom and courage from design; then from definition and guide of landscape value to human cognition and research of desire even to the research of relationship of design considerations; finally from system scope of design-seeking for choice-choosing topic and organizing idea-sight tasting. The requirements of this landscape pose a severe test to designers anytime and designers' cognitions to its every part will affect the influence on ecological environment late in the project. I want to appeal to the public that environmental landscape design cannot be designed simply for the beautiful but for the whole natural and human ecological system.

Is landscape design creating value or delivering value? The landscape design based on this value can make people in it whether or not have sense of belonging and identity. In my personal opinion, the value of landscape is from people's understanding and definition to landscape. Landscape design should not let the simple functionalism create value but deliver value information by people's concept and method of "human is the landscape". This idea is from people's life style and way of thinking, moreover landscape design aiming to choose, advocate, understand and respect but not to create. Its propose is also not to intervene rashly and artificially under the simple functionalism for functions are just the appendants of life but not the meaning and purpose of life itself.

Therefore, the concept "no design" and "non-existence design" are proposed for modern urban landscape design to remind people to adjust measures to local conditions but not to meaninglessly expand the area or to increase investment just to realize the landscape effects, even to take destroying environment as the price.

\section{CONCLUSION}

No matter it is about interior design, architectural design or landscape design, as a designer, I can't help asking: Is there any design that cannot be done? Designers should do certain things and refrain from doing other things. For the designers who dare do anything and can do everything, are your designs boring?

All designs exist for "survival", for what be born and for what exist; for what live such a way, and what finally existed. The urban landscape design is to preserve and present the true features of natural texture, inheriting and carrying forward the local culture and architectural feature originally. It should be capable to make people feel the strong ecological beauty and bring them sense of belonging and cognition by the immersive scenery. Economic positive benefits also should be brought. In order to find the balance between ecological pursuit and market development, designers should take the long view and not focus on the immediate interests or effects. Design also should develop in a long-term way meanwhile the cultural inheritance and the economic interest in landscape design also taken into comprehensive consideration. Therefore, we as a new generation of designers shall make more professional efforts.

\section{REFERENCES}

[1] Original Copies: Architectural Mimicry in Contemporary China. Bianca Bosker. University of Hawaii Press. 2013

[2] Environmental Ethics and Ecological Crisis and Its Outlet. Liu Yuli. World Affairs Press.2012.

[3] Urban Landscape Art Design. Guo Weimin, Shi Ming. Southeast University Press.2011.

[4] Ecological Crisis in Condition of Modernity. Wu Xianwu. Anhui Normal University Press.2010.

[5] Remediation and Protection of the Village Reconstruction. Tian Jianwen. China Agriculture Press.2009.

[6] View - System - Extension-Conception and Practice of Planning and Design. Li Jianwei. Hydraulic and Electric Power Press.2008. 